\title{
Impact and Ethics: A Meta-Analysis of Library Impact Studies
}

\author{
M. Brooke Robertshaw \\ Oregon State University, USA
}

\author{
Andrew Asher \\ Indiana University, USA
}

\begin{abstract}
${ }^{1}$
Following trends in higher education that emphasize quantitative analytical approaches to learn about educational outcomes, academic libraries are increasingly turning to "big data" methods in an attempt to demonstrate their impacts on student learning and demonstrate their value to the university's educational mission. By applying learning analytics techniques to library use and instructional data, libraries have especially focused on attempting to measure the impact of the library on student retention and achievement measures. $^{2}$
\end{abstract}

This presentation has two purposes. The first purpose is to discuss the methodological issues which were detected while conducting a meta-analysis on library impact studies. The second purpose is to present findings from a meta-analysis conducted on studies that were published between 1 January 2008 and 30 April 2018.

There are currently debates within the learning analytics field about informed consent and transparency when undertaking these methodological approaches. ${ }^{3}$ These debates exist because learning analytics studies require large datasets of personally identifiable information (PII) that could be inherently risky due to the potential for breaching the confidentiality and privacy rights of individuals and groups within the dataset. The methodological issues that were detected while conducting this meta-analysis fall within this this debate because these studies subject individuals in library datasets to the same risks outlined above.

This presentation will also explore the results of the statistical findings from this meta-analysis of learning analytics studies in libraries that examine the effects of library use on students' retention and GPA. Based on these results, we will delve back into the debate about privacy, transparency, learning analytics, and libraries. We will examine the issue through two lenses-a pragmatic lens, and an ethical lens. While we recognize the institutional importance of these types of studies as well as the environmental conditions that create pressure on libraries to participate in learning analytics initiatives, we will also question the beneficence of these studies from a research ethics point of view.

1. This paper will be published in Library Trends for publishing. View the pre-print on the web at: https://ir.library.oregonstate.edu/concern/articles/qn59q8754.

2. Crawford, 2015; Cox \& Jantti, 2012; Soria, Fransen \& Nackerud, 2013.

3. Prinsloo \& Slade, 2013; Richards \& King, 2013. 